\title{
DEVELOPMENT AND VALIDATION OF SOCIAL COMPARISON SCALE FOR WOMEN WITH INFERTILITY IN PAKISTAN
}

\section{Anila Sadaf Mubashir ${ }^{\mid 凶}$, Syeda Shahida Batool'}

\section{ABSTRACT}

OBJECTIVE: The study was designed to construct a valid and reliable social comparison scale for women with infertility (SCS-WI) in Pakistan.

METHODS: A mixed-method approach with purposive sampling techniques was used to construct the scale. Study duration was 13 months and was set in private and government hospitals and clinics of major cities of four provinces of Pakistan. Factor structure of 37 item with primary infertility was explored through exploratory factor analysis (EFA) on a sample of 215 women with primary infertility with age range from $20-45\left(M_{\text {age }}=31.03 ; S D=6.18\right)$ years. The obtained factor structure of Social Comparison Scale for Women with Infertility (32 items) was further confirmed through confirmatory factor analysis (CFA) on a sample of 210 women with primary infertility whose ages ranged between 20 years and 45 years $\left(M_{\text {age }}=32.42, S D=5.49\right)$.

RESULTS: Principal component analysis (PCA) with Varimax rotation method yielded three factors (viz., social distress, emotional burden and personal incapacities) and accounted for $63.37 \%$ variance and all 32 items of the scale were retained. The CFA supported the measurement structure of SCS-WI retained after EFA. The Cronbach's alpha coefficient for the scale was 0.95 (alphas range from $0.85-0.90$ for subscales) with sound convergent and divergent validity $(r=0.37, p=0.05)(r=-0.70, p<0.00 I)$ respectively. Test re-test reliability was $(r=0.93, p<0.001)$.

CONCLUSION: Social comparison scale for women with infertility is a valid scale with good items homogeneity, internal consistency and a revelatory pattern of validity.

KEY WORDS: Infertility, Female (MeSH); Social comparison (Non-MeSH); Scale development (Non-MeSH); Mixed method (Non-MeSH); Varimax rotation (Non-MeSH); Convergent validity (Non-MeSH).

THIS ARTICLE MAY BE CITED AS: Mubashir AS, Batool SS. Development and validation of social comparison scale for women with infertility in Pakistan. Khyber Med Univ J 2019;II(3):I29-39. DOI: 10.35845/kmuj.2019.18467

\section{INTRODUCTION}

n nfertility is a global issue affecting 8$12 \%$ of the couples and it has high social implications.' In Pakistan, the rate of infertility is escalating with the passage of time and about $8 \%$ population of Pakistan face the infertility problems. Infertility is taken as a major catastrophe by most couples as being a parent is conforming in women's life. ${ }^{3}$ From ancient past most societies holds a strong belief that children are considered to raise well-being of parents. ${ }^{4}$ It is common observation that if a couple fails to conceive after a year of marriage people start making social comparison of this couple especially women with reference to other children bearing mothers.

Infertility refers to "the failure to conceive a pregnancy after a year or more of regular intercourse without
I. Department of Psychology, Government College University, Lahore, Pakistan. Email『: a.nila_s@hotmail.com

$\begin{array}{ll}\text { Date Submitted: } & \text { June 25, } 2018 \\ \text { Date Revised: } & \text { May 08, 2019 } \\ \text { Date Accepted: } & \text { May 10, 2019 }\end{array}$

contraceptives is infertility" ${ }^{5}$. The fundamental basis of not conceiving can be due to the problem in one of the partner and it can be caused by different problems. Common causes of infertility in women could be the process of ovulation, polycystic ovarian syndrome, Endometriosis, or blocked fallopian tubes. $^{5}$

Infertility affects the life of a married women in the form of constant marital dissonance, instability, husband's remarrying or wife returned to their parent's home by their in laws or husbands, threats for divorce by husband, stigmatization by husbands and in-laws for being infertile found which seriously affects well-being, social status of women and causes mental illness in women of Pakistan. ${ }^{6}$ The aftermaths of infertility are multifarious comprising of societal sways and personal distress. Infertility is a negative incident of life and affects personal, social, physical, psychological and economical well-being of a woman, ${ }^{8}$ feelings of anger, frustration, and aggression often accompanies it, ${ }^{9}$ causing stress thereby lowering down their wellbeing. It is a core source of diminished health and reduced levels of social wellbeing and results in significant pain and distress and that a large number of couples go to great lengths for overcoming this problem. Infertility leads to psychological distress as well as an intensive amount of social suffering. ${ }^{10,11}$ Social comparison as an important construct determines the well-being, and its momentousness in shaping individual worthiness has been widely supported by subjective wellbeing literature. ${ }^{12}$ Social comparison may create more problems for the couple particularly women with infertility than the infertility itself. Social comparison consists of perceptions of personal superiority or inferiority. ${ }^{13}$ Social comparison is a way of deciding own social and personal worth based on 
TABLE I: MEAN VALUES AND STANDARD DEVIATION OF RESPONSES FOR EACH OF THE 37 ITEMS OF SCS-WI $(n=30)$

\begin{tabular}{|c|c|c|c|c|}
\hline Item No & Mean & SD & Min & Max \\
\hline SCS-WI I & 2.63 & 1.24 & 0 & 4 \\
\hline SCS-WI 2 & 3.23 & 0.85 & $\mathrm{I}$ & 4 \\
\hline SCS-WI 3 & 2.60 & 1.45 & 0 & 4 \\
\hline SCS-WI 4 & 2.43 & 1.50 & 0 & 4 \\
\hline SCS-WI 5 & 2.87 & 1.22 & 5 & 4 \\
\hline SCS-WI 6 & 3.35 & 0.92 & 0 & 4 \\
\hline SCS-WI 7 & 2.24 & 1.31 & 0 & I \\
\hline SCS-WI 8 & 1.40 & 0.96 & 0 & 4 \\
\hline SCS-WI 9 & 1.93 & 1.72 & 0 & 4 \\
\hline SCS-WI I0 & 1.83 & 1.51 & 0 & 4 \\
\hline SCS-WI II & 2.07 & 1.48 & 0 & 4 \\
\hline SCS-WI I2 & 2.30 & 1.55 & 0 & 4 \\
\hline SCS-WI I3 & 1.97 & 1.52 & 0 & 4 \\
\hline SCS-WI I4 & 2.10 & 1.42 & 0 & 4 \\
\hline SCS-WI I5 & 2.00 & 1.64 & 0 & 4 \\
\hline SCS-WI I6 & 3.13 & 1.16 & 0 & 4 \\
\hline SCS-WI I7 & 3.07 & 1.01 & $\mathrm{I}$ & 4 \\
\hline SCS-WI I8 & 2.03 & 1.56 & 0 & 4 \\
\hline SCS-WI 19 & 1.53 & 1.45 & 0 & 4 \\
\hline SCS-WI 20 & 1.57 & 1.50 & 0 & 4 \\
\hline SCS-WI 21 & 1.60 & 1.52 & 0 & 4 \\
\hline SCS-WI 22 & 2.07 & 1.58 & 0 & 4 \\
\hline SCS-WI 23 & 1.87 & 1.38 & 0 & 4 \\
\hline SCS-WI 24 & 1.49 & 1.65 & 0 & 4 \\
\hline SCS-WI 25 & 1.87 & 1.61 & 0 & 4 \\
\hline SCS-WI 26 & 2.33 & 1.59 & 0 & 4 \\
\hline SCS-WI 27 & 2.83 & 1.66 & 0 & 4 \\
\hline SCS-WI 28 & 2.83 & 1.41 & 0 & 4 \\
\hline SCS-WI 29 & 2.03 & 1.42 & 0 & 4 \\
\hline SCS-WI 30 & 1.43 & 1.45 & 0 & 4 \\
\hline SCS-WI 31 & 2.20 & 0.76 & 0 & 4 \\
\hline SCS-WI 32 & 3.07 & 1.31 & 0 & 4 \\
\hline SCS-WI 33 & 3.37 & 0.99 & $\mathrm{I}$ & 4 \\
\hline SCS-WI 34 & 2.77 & 1.43 & 0 & 4 \\
\hline SCS-WI 35 & 1.93 & 1.50 & 0 & 4 \\
\hline SCS-WI 36 & 1.23 & 0.62 & $\mathrm{I}$ & 3 \\
\hline SCS-WI 37 & 2.67 & 1.24 & $\mathrm{I}$ & 4 \\
\hline Total SCS-WI & 72.47 & 27.0 & 32 & 116 \\
\hline
\end{tabular}

SCS-WI: social comparison scale for women with infertility

how one measure up against others. ${ }^{13}$

Social comparison is one of the significant element that play a vital part in the prediction of psychosocial adjustment of women with infertility and due to social comparison women with infertility suffer from misjudgements or prejudices in different situations by their colleagues and relatives. Further women with infertility are found to be involved in more negative views than the child bearing mothers. Social comparison is found to construct stigma among couple with infertility. ${ }^{14}$

In Pakistani society, family pressure on husband for second marriage to have children is reported to be the source of distress and insecurity in marital relationship. ${ }^{12}$ Further women with infertility faces emotional harassment, seclusions from the family celebrations, stigmatization, less health care facilities as before, occasionally negative attitudes by family members ${ }^{13}$ along with low subjective well-being, high negative feelings, less positive feelings, low self-esteem, poor social support, less freedom and less opportunities. ${ }^{14}$

The lack of education and adequate biological understanding about the problem leads to an extensive stigmatization of such women. It has been identified in such countries that bearing children is a pre-requisite for women to strengthen their foothold in their husband's home. Social isolation and alienation is also widely seen in such societies. The couple has to confront familial and societal pressures, ${ }^{6}$ and when they compare themselves with child bearing mothers, they feel demotion in their status and rank in society which seems to be painful and disturbing creating lot of psychological problems especially depression in the woman with infertility. ${ }^{15}$

The psychological significance of a comparison depends on the social status of an individual. Giving birth to a child for women is a mean for achieving a better social status and rank and which is a mean of achieving the totality of motherhood. ${ }^{16}$ The significant climacteric for all women that enhances women status in the family and society, give purpose to life and make life complete is motherhood. ${ }^{16}$ On the other hand, women with infertility are rated by the society as being incomplete due to their inability to achieve motherhood. They are also subject to marginalization and are also subject to a systematic and progressive devaluation. ${ }^{17}$

King and Meyer ${ }^{17}$ had identified that the ideas of class, social rank and race are reflected in terms of the benefits associated with infertility. One example is that of the provision of treatment for infertility of women belonging to higher social classes. On the other hand, the fertility of women belonging to the lower social strata was controlled in the former societies. The researchers also stated that social rank determines the distribution of reproductive benefits for women in developing and developed regions. In United States, there are a 
number of regions in which treatment for infertility is mandated to be provided by insurers for middle class women. However, no such treatment options are provided to those belonging to the lower social classes. Similarly, a wide range of dualistic natal policies have been seen in many other countries of the world. This is an indication that infertility is strongly linked with social rank. $^{17}$

Social comparison serves the formation of social ranks and evaluates one's relative rank and social standing. Social comparison is one of the component of social rank. ${ }^{13}$ The literature provides evidence that unfavourable, negative or upward social comparison is associated with feelings of inadequacy, inferiority and with a variety of psychological difficulties including depression. Depressive symptomatology often emerges as a direct response to losing one's rank when making comparison with others in the society and to develop a conception of oneself as being a loser. Depression is initiated when one starts to categorize oneself as being a hopeless liability and one develops the feelings that the group is better without having oneself as a part of them. It is evident the social rank tends to focus on varying forms of power in relationships including dominant in comparison to submissive behaviours. ${ }^{13}$

State of social comparison among women with infertility is different from general social comparison; so a strong need was felt to develop a tool specifically for women with infertility which can screen the state of social comparison in context of infertility. Moreover there are many measurement scales which were developed to screen out issues related to infertility but no such scale is available to measure the construct of social comparison among women with infertility. Thus, present study aimed to develop and validate Social Comparison Scale for women with infertility. The objectives of the study were

I. To develop Social Comparison Scale for Women with Infertility (SCS-WI).

2. To explore the initial factor structure of Social Comparison Scale for Women with Infertility.

3. To confirm the factor structure of Social Comparison for Women with Infertility.

4. To find convergent and discriminate validities of the scale.

5. To determine the reliability of the measure of SCS-WI primary infertility.

\section{METHODS \& RESULTS}

The study is divided into five phases. In phase I, an item pool was generated, whereas, in phase II, pilot study was carried out. In phase III factor structure of the scale was determined through exploratory factor analysis, while in phase IV factor structure of the Social Comparison Scale for Women with Infertility was confirmed through confirmatory factor analysis. In phase $\mathrm{V}$ validation of Social Comparison Scale for Women With Infertility was done.

Phase I: Generation of item pool: The items of the study were generated using semi structured interviews and going over the relevant literature using
TABLE II: FACTOR LOADINGS, MEAN AND STANDARD DEVIATION ( $\mathbf{N}=215)$

\begin{tabular}{|c|c|c|c|c|c|}
\hline \multirow{2}{*}{ Old Item No. / New Item No. } & \multicolumn{3}{|c|}{ Factors } & \multirow{2}{*}{ Mean } & \multirow{2}{*}{ Max } \\
\hline & I & 2 & 3 & & \\
\hline SC-WI 3I/ SC-WI I8 & 0.87 & 0.27 & 0.12 & 2.20 & 1.56 \\
\hline SC-WI 20/ SC-WI I7 & 0.87 & 0.21 & 0.20 & 2.07 & 1.56 \\
\hline SC-WI 25/ SC-WI 22 & 0.85 & 0.19 & 0.19 & 2.03 & 1.63 \\
\hline SC-WI I9/SC-WI I6 & 0.79 & 0.27 & 0.26 & 2.20 & 1.53 \\
\hline SC-WI 22 /SC-WI 19 & 0.77 & 0.26 & 0.25 & 2.23 & 1.55 \\
\hline SC-WI 26/SC-WI 23 & 0.75 & 0.23 & 0.25 & 2.38 & 1.54 \\
\hline SC-WI 35/SC-WI 30 & 0.71 & 0.32 & 0.20 & 2.47 & 1.51 \\
\hline SC-WI I8/SC-WI I5 & 0.67 & 0.22 & 0.45 & 2.49 & 1.45 \\
\hline SC-WI 24/SC-WI 2 I & 0.67 & 0.45 & 0.17 & 2.56 & 1.56 \\
\hline SC-WI 23/SC-WI 20 & 0.64 & 0.46 & 0.23 & 2.07 & 1.56 \\
\hline SC-WI 30/SC-WI 32 & 0.59 & 0.20 & 0.34 & 2.05 & 1.50 \\
\hline SC-WI 9/ SC- WI 6 & 0.57 & -0.13 & 0.28 & 2.20 & 1.53 \\
\hline SC-WI I I/SC-WI 8 & 0.53 & 0.30 & 0.51 & 2.50 & 1.41 \\
\hline SC-WI 27/SC-WI 24 & -0.43 & -0.31 & -0.14 & 1.65 & 1.71 \\
\hline SC-WI I5/SC-WI I2 & -0.42 & -0.08 & -0.34 & 1.59 & 1.61 \\
\hline SC-WI 33/SC-WI 28 & 0.15 & 0.78 & 0.13 & 3.33 & 1.08 \\
\hline SC-WI 32/SC-WI 26 & 0.23 & 0.76 & 0.11 & 3.27 & 1.07 \\
\hline SC-WI 28/SC-WI 27 & 0.32 & 0.65 & 0.36 & 3.01 & 1.30 \\
\hline SC-WI 2//SC-WI 2 & 0.07 & 0.65 & 0.42 & 2.46 & 1.45 \\
\hline SC-WI 5//SC-WI 5 & 0.33 & 0.61 & 0.17 & 1.59 & 1.61 \\
\hline SC-WI 3/SC-WI 3 & 0.26 & 0.60 & 0.45 & 2.30 & 1.50 \\
\hline SC-WI 34/SC-WI 29 & 0.28 & 0.55 & 0.52 & 2.91 & 1.29 \\
\hline SC-WI 37/SC-WI 3I & 0.33 & 0.53 & 0.41 & 2.99 & 1.24 \\
\hline SC-WI I2/SC-WI 9 & 0.33 & 0.17 & 0.72 & 2.46 & 1.45 \\
\hline SC-WI I0/SC-WI 7 & 0.33 & 0.19 & 0.72 & 2.31 & 1.51 \\
\hline SC-WI I3/SC-WI I0 & 0.42 & 0.17 & 0.71 & 2.30 & 1.50 \\
\hline SC-WI I4/SC-WI II & 0.35 & 0.30 & 0.71 & 2.54 & 1.49 \\
\hline SC-WI I/SC-WI I & 0.01 & 0.44 & 0.62 & 2.50 & 1.41 \\
\hline SC-WI 4/SC-WI 4 & 0.26 & 0.48 & 0.59 & 2.54 & 1.49 \\
\hline SC-WI I6/SC-WI I3 & 0.17 & 0.47 & 0.54 & 3.28 & 1.02 \\
\hline SC-WI I7/SC-WI I4 & 0.34 & 0.45 & 0.50 & 3.05 & 1.20 \\
\hline SC-WI 29/SC-WI 25 & 0.41 & 0.44 & 0.45 & 2.03 & 1.63 \\
\hline Eigen & 16.35 & 2.64 & 1.41 & & \\
\hline$\%$ & 51.11 & 8.24 & 4.41 & & \\
\hline
\end{tabular}




\begin{tabular}{|c|c|c|c|c|}
\hline \multicolumn{5}{|c|}{$\begin{array}{l}\text { TABLE III: FINAL FACTORS, PERCENTAGE OF VARIANCE } \\
\text { AND ALPHA COEFFICIENTS OF SOCIAL COMPARISON SCALE FOR } \\
\text { WOMEN WITH PRIMARY INFERTILITY }(\mathbf{N}=\mathbf{2} 15)\end{array}$} \\
\hline Factor Label & $\begin{array}{l}\text { Final (with new item no.) } \\
\text { Items Retained }\end{array}$ & $\begin{array}{l}\text { Final } \\
\text { Items }\end{array}$ & Variance & $\begin{array}{c}\text { Alpha } \\
\text { coefficients }\end{array}$ \\
\hline FI Social Distress & $\begin{array}{c}6,8,12,15,16,17,18,19 \\
20,21,22,23,24,30,32\end{array}$ & 15 & $51.11 \%$ & 0.89 \\
\hline F2 Emotional Burden & $2,3,5,26,27,28,29,31$ & 8 & $8.24 \%$ & 0.90 \\
\hline F3 Personal Incapacity & $1,4,7,9,10,11,13,14,25$ & 9 & $4.41 \%$ & 0.91 \\
\hline SCS-WI & $\mathrm{FI}, \mathrm{F} 2, \mathrm{~F} 3$ & 32 & $63.76 \%$ & 0.94 \\
\hline
\end{tabular}

TABLE IV: ITEMS TOTAL CORRELATIONS FOR SUB SCALES OF 32-ITEM SOCIAL COMPARISON SCALE FOR WOMEN WITH PRIMARY INFERTILITY $(n=2 I 5)$

\begin{tabular}{|c|c|c|c|c|c|}
\hline Subscales and Items & $\mathbf{r}$ & Subscales and Items & $\mathbf{r}$ & Subscales and Items & $\mathbf{r}$ \\
\hline Social Distress & & 24 & -0.50 & Personal Incapacities & \\
\hline 6 & 0.44 & 33 & 0.66 & $\mathrm{I}$ & 0.56 \\
\hline 8 & 0.77 & 30 & 0.72 & 4 & 0.70 \\
\hline 12 & -0.48 & Emotional Burden & & 7 & 0.69 \\
\hline 15 & 0.79 & 2 & 0.57 & 9 & 0.68 \\
\hline 17 & 0.79 & 3 & 0.70 & 10 & 0.73 \\
\hline 18 & 0.77 & 5 & 0.60 & 11 & 0.75 \\
\hline 19 & 0.78 & 27 & 0.73 & 13 & 0.62 \\
\hline 20 & 0.76 & 26 & 0.56 & 14 & 0.71 \\
\hline 21 & 0.76 & 38 & 0.55 & 25 & 0.79 \\
\hline 22 & 0.74 & 29 & 0.74 & & \\
\hline 23 & 0.74 & 31 & 0.69 & & \\
\hline
\end{tabular}

TABLE V: MEAN, STANDARD DEVIATION, CRONBACH'S ALPHA AND RESPONSE RANGES ( $N=215)$

\begin{tabular}{|l|c|c|c|c|c|}
\hline \multicolumn{1}{|c|}{ Scale } & K & M (SD) & $\alpha$ & Potential Range & Actual Range \\
\hline (SCS-WI) & 32 & $8 I .85(27.67)$ & 0.94 & $0-128$ & $10-120$ \\
\hline FI Social Distress & 15 & $30.10(I 2.40)$ & 0.89 & $0-60$ & $3-50$ \\
\hline F 2 Emotional Burden & 9 & $21.06(6.38)$ & 0.90 & $0-36$ & $4-32$ \\
\hline F 3 Personal Incapacities & 8 & $24.76(7.49)$ & 0.91 & $0-32$ & $1-32$ \\
\hline
\end{tabular}
Note. kno. of items. a:Cronbach's alpha

TABLE VI: STANDARDIZED CFA SOLUTION OF SOCIAL COMPARISON SCALE FOR WOMEN WITH INFERTILITY $(n=210)$

\begin{tabular}{|l|c|c|c|c|c|c|c|c|}
\hline Model & IFI & TLI & CFI & RMSEA & $\boldsymbol{P}$ & $\mathbf{D f}$ & $\chi \mathbf{2}$ & $\chi \mathbf{2} / \mathbf{d f}$ \\
\hline Initial Model & 0.84 & 0.83 & 0.84 & 0.10 & 0.000 & $46 \mathrm{I}$ & 1356.33 & 2.94 \\
\hline Revised Model & 0.87 & 0.86 & 0.87 & 0.10 & 0.01 & $32 \mathrm{I}$ & $99 \mathrm{I} .62$ & 3.08 \\
\hline Final Model & 0.91 & 0.90 & 0.91 & 0.08 & 0.01 & 317 & 790.71 & 2.49 \\
\hline
\end{tabular}

IFI = incremental fit index, CFI = comparative fit index, TLI = Tucker Lewis Index Model. Final Model items reduced from 32 to 27 (item no. 5, 8 I5, 18, 20 deleted)

TABLE VII: OVERALL MEAN, STANDARD DEVIATION, CRONBACH'S ALPHA, MAXIMUM SCORE, MINIMUM SCORE $(\mathrm{N}=210)$

\begin{tabular}{|l|c|c|c|c|c|c|}
\hline Scale & $\boldsymbol{K}$ & Final Items retained & $\mathbf{M}($ SD) & $\alpha$ & Min & Max \\
\hline SCS-WI & 27 & $1-27$ & $55.17(23.48)$ & 0.95 & 19 & 103 \\
\hline Social distress & II & $\begin{array}{c}5,10,13,14,15,16, \\
\text { I7, I8, 19,25, 27 }\end{array}$ & $21.28(10.23)$ & 0.90 & 3 & 44 \\
\hline Emotional burden & 7 & $2,3,21,22,23,24,26$ & $14.37(6.35)$ & 0.85 & I & 28 \\
\hline Personal Incapacities & 9 & $\mathrm{I}, 4,6,7,8,9,1 \mathrm{I}, 12,20$ & $17.43(7.99)$ & 0.87 & 2 & 33 \\
\hline
\end{tabular}

guidelines provided by Burisch. ${ }^{18}$ We interviewed twelve women with primary infertility. Interviews were transcribed and analyzed through Thematic Analysis yielding three superordinate themes i.e. Social Distress, Emotional Burden and Personal Incapacities. On the basis of these themes and social rank theory, ${ }^{19}$ initial pool of items was generated in Urdu language. The pool of items was handed over to a committee of five judges (three Psychologists and two Gynaecologists) for sifting the items on selection criteria that included construct fidelity, clarity of statement, conceptual validity, comprehensibility and item redundancy. A consensus of 37 items was finally reached by the judges retained for SCS-WI. Item sequence in the scale was shuffled to randomize the items any for possible carry- over effects. The response format on items was based on 5-point Likert type scale ( 0 =strongly disagree, $\mathrm{I}=$ disagree, $2=$ indecisive, $3=$ strongly agree, $4=$ strongly agree). High score on the scale represents more social comparison and low score represent less social comparison

Phase II: Pilot Study: Pilot study was executed to ensure the comprehensibility and psychometric cleansing of the items by engaging 30 women with primary infertility in the pilot study from Rawalpindi city using purposive sampling strategy. The age range of the participants was 20 to 45 years $\left(M_{\text {age }}=31.37, S D=5.18\right)$. It supported the process of item selection by determining the difficulty level and clarity of items. It ensured the exclusion of repetitive, ambiguous and redundant items in the study as per the study participants' suggestions. In order to ascertain the normality of this sample and data a Shapiro-Wilk test ${ }^{19}$ was used on dependent measure where analysis $\mathrm{W}(30)=0.94, \mathrm{p}>0.05$, indicated data was normally distributed in the group.

Phase III: Factor Structure and Internal Consistency

To determine the internal consistency and factor structure of SCS-WI the items were analyzed through EFA. Cronbach alpha, items total scale correlation and items sub-scales 
correlations were calculated to determine the reliability and internal consistency of the scale.

Sample: Purposive sample of 230 women with primary infertility were later recruited who were willing to take part in the study. The sample was taken from government and private hospitals, clinics and infertility centres of major cities of four provinces of Pakistan fifty five percent of participants came from different cities of Punjab namely Rawalpindi, Islamabad, Multan and Lahore and fifteen percent each from provinces of Khyber Pakhtunkhwa (Peshawar and Mardan) Baluchistan (Quetta, Khuzdar and Qila saifullah) and Sindh (Karachi, Sukkhur and Hyderabad). The age range of the participants were 20- $45\left(M_{\text {age }}=31.03\right.$; $\mathrm{SD}=6.18$ ) years. The educational level of the participants ranged from primary to post Masters and none were illiterate. Participants belonging to lower, middle and upper socioeconomic classes and were cooperative during the completion of the questionnaires, however, eight participants left the study incomplete due to personal reasons and six could not return the questionnaires and their data was excluded from the study and the final sample comprised of 215 women with infertility.

Instrument: Social Comparison Scale for Women with Infertility comprising of 37 items was used in the study.

Procedure: Permission from the authorities of the hospital, clinics and fertility centres was sought for administration of SCS-WI. Participants were informed about the purpose of study and informed consent was taken from the participants before administering the scales. They were asked to complete the questionnaires on the spot and their queries were answered before, during and after the scale was filled. Most participants returned the questionnaire on the spot while others took some time and returned the questionnaires after few days to the researcher personally and by post as well.

Results: Before factor analysis of the data certain assumptions (For example sample size, normality, communalities, outliers among cases and linearity) were tested and was found to fulfil the criteria provided by Field. ${ }^{20}$ Sample size was determined with the ratio of five participants to each variable in the study. The Kaiser-Meyer-Olkin ${ }^{22}$ measure of sampling adequacy was 0.95 , which was excellent for structure detection and Bartlett's Test of Sphericity ${ }^{21}$ was highly significant $X^{2}(496)=5606.98, p<0.00$ I which indicated that factor analysis is appropriate for these data.

Table II shows factor loadings and communalities of 32 items on three factors. Principal Component Analysis (PCA) yielded five factor solutions. Following the criteria of Kaiser $\mathrm{HF}^{21}$ three well defined, interpretable, clear and accurate factors were retained on the basis of Scree plot, Eigen values $>1.0$, factor loadings greater than 40 in each sub-scale and theoretical relevance thereby discarding five items from factor 4 and factor 5 . The final factors retained were labelled as Social Distress ( $\mathrm{FI}$, factor I), Emotional Burden (F2, factor 2) and Personal Incapacity (F3, factor 3). The Eigen value for factor $I$ is 16.35; factor 2 is 2.64 and factor 3 is $1.4 \mathrm{I}$ and accounted for $63.76 \%$ of the total variance. Out of 37 items, 5 items were deleted that has factor loading less than 0.40 with Eigen value less than I. Detail of each factor is given below (see Table III).

Factor I (Social Distress): Items (6, 8, $12,15,16,17,18,19,20,21,22,23,24$,

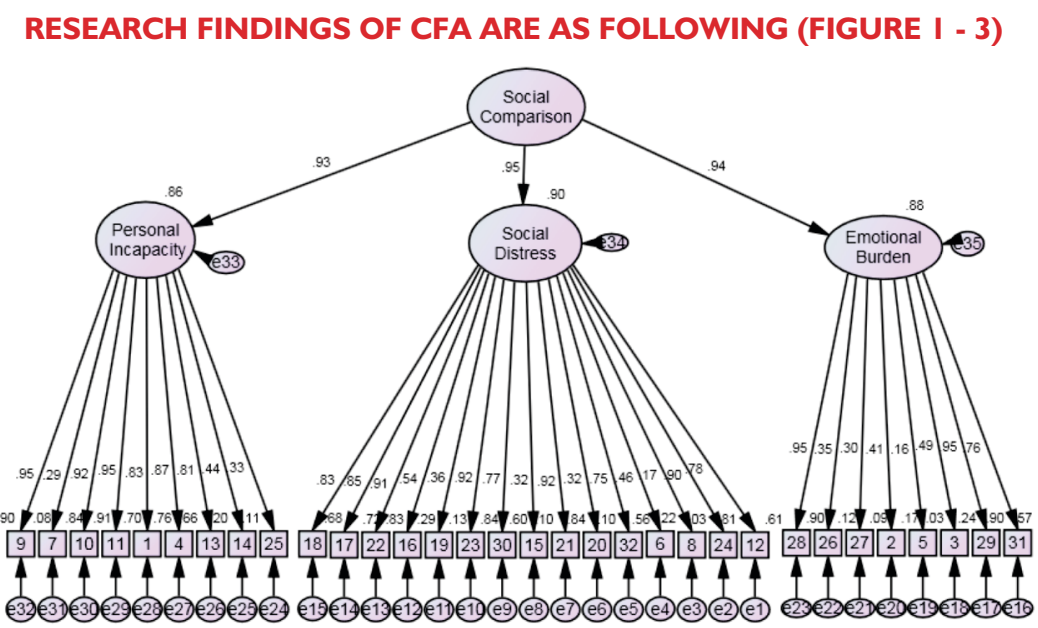

Figure I: Initial Model Social Comparison Model Scale for Women with Infertility (SCS-WI) 32-item Scale

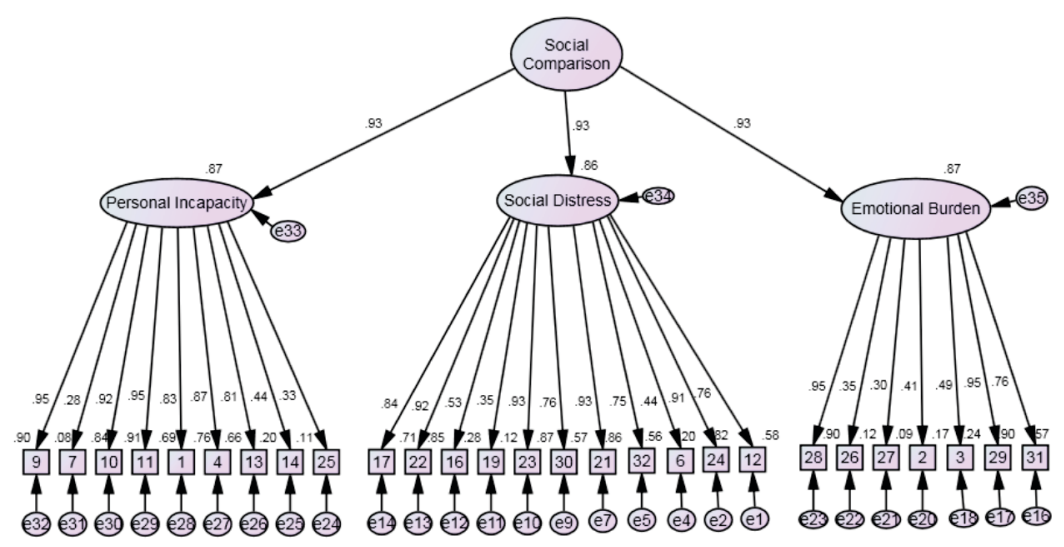

Figure 2: Revised Model Social Comparison Scale for Women with Infertility (SCS-WI) Model 27-item Scale 


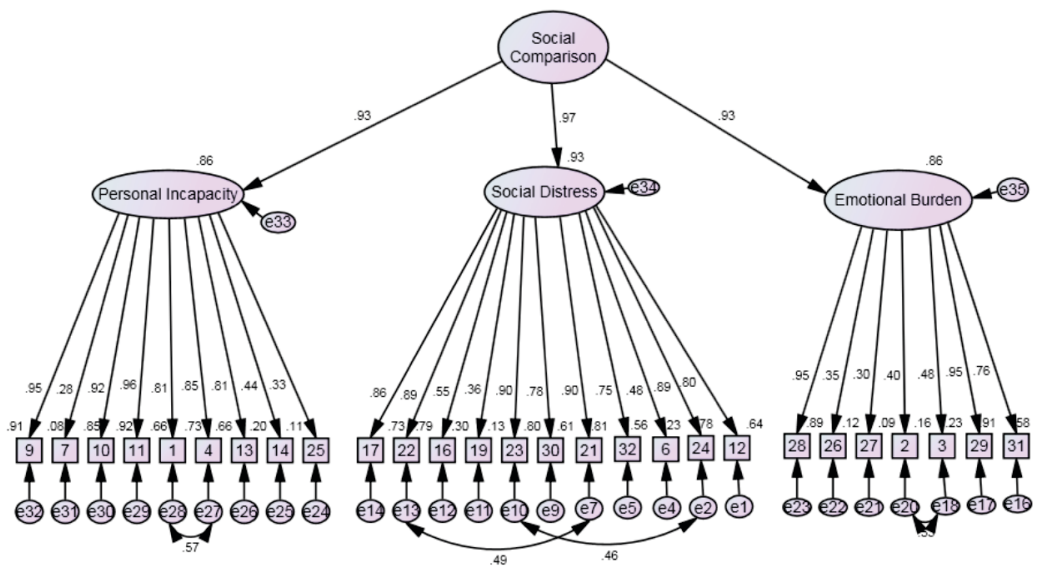

Figure 3: Final Model social comparison scale for women with infertility (SCS-WI) 27-item Scale (With Modification Indices)

32, 30) had independent loading on factor I and represent social distress of Social Comparison Scale for Women with infertility. For Instance, social factors that have an impact on women with infertility like diminished social status, respect and importance in family, social stigmatization, negative and critical attitude of people, reduced liking in family especially in-laws, rejection by family, blaming by family, reduction in love and attention by husband, left out by husband, cold attitude of husband, uncooperative husband towards treatment, threats of expelling from husband's home, threats of second marriage by husband and inlaws, distant relations with husband, gap in communication with husband, in-laws thinking of women with infertility as useless and take her granted for all household chores and other tasks, social isolation, avoiding social gathering etc. It explained $51.22 \%$ of variance.

Factor 2 (Emotional Burden): Items $(2,3,5,26,27,28,29,31)$ had independent loading on factor 2 labelled as "Emotional Burden" sub scale of Social Comparison Scale for Women with infertility. These items relate to emotional factors that have an impact on women with infertility like feelings of sadness, sorrow, worthlessness, loneliness, helplessness, hopelessness, negative feelings, depression, anger, anxiety, aggression, frustration, irritability, distress, grief, loss of happiness, reduced interest in daily activities, envy, jealousy, insecurity shame, humiliation etc. It explained $8.24 \%$ of variance.

Factor 3 (Personal Incapacity): The items I, 4, 7, 9, 10, II, 13, 14, 25 had independent loading on factor 3 representing the third subscale labelled as "Personal Incapacity" subscale of Social Comparison Scale for Women with infertility. The items of this subs scale are related to personal factors that effects women with primary infertility like feelings of inferiority, self blaming, fatigue, less resourcefulness, low self esteem, low confidence, reduced eye contact, feelings of physical and mental illness and weakness, meaningless life, feeling incomplete, feelings of left out, negative future apprehensions, reduced attraction, decreased sexual attraction, negligence of personal care and hygiene etc). It explained $4.41 \%$ of variance.

The factorial validity of the scale was demonstrated on empirical and theoretical grounds. The final scale came up with 32 items and three well delineated factors i.e., social distress ( 15 items), emotional burden (8 items) and personal incapacity ( 9 items).

Reliability Analysis: Item-total correlation was run to see the internal consistency of the scale. Results in table $\checkmark$ presented that each item of social comparison scale for women with infertility correlated ( $r$ ranging from 0.44 to 0.78 ) with the sum of total items. Moreover, mean inter-item correlation was 0.50 . Thus, all items may be considered valid and reliable indicators of Social Comparison scale for Women with infertility.

Test of Cronbach alpha was run to see the internal consistency of the total and sub scale scores.

Table $V$ shows the mean, standard deviation, Cronbach's alpha, response range and skewness values. It was found that overall Cronbach's alpha for Social comparison was good (a ranging from 0.89 to 0.94 ) which is good along with the potential range and actual range of the SCS-WI. Furthermore, if we compare the mean of the sample with the potential range of the score on the relevant scale, it appears that on SCS-WI the mean score is 81.85 and the maximum potential range is $0-128$ which indicates that average score of the sample lies on the higher direction showing higher social comparison in women with primary infertility. As far as the Factor I i.e., social distress is concerned, the mean score is 30.10 and the maximum potential range is $0-60$ indicating that the score of the sample lies on the average side, whereas, a mean score of 21.06 on factor 2 i.e., emotional Burden with potential range of 0-36 indicates that the sample mean lies on higher side on this factor. Lastly, the sample mean on the Factor 3 i.e., personal incapacities is 24.76 with potential range of $0-32$ indicating sample mean on higher side in this factor as well.

Phase IV: Confirmatory Factor Analysis (CFA): In this phase the factorial validity of the Social Comparison Scale for Women with Infertility (SSC-WI) was found out. The scale was analyzed and the final items of the scale were retained after assuring the appropriate structure of the items. To confirm factor structure of the scale confirmatory factor analysis was employed.

Sample: Purposive sample of 230 women with primary infertility who were willing to take part in the study were recruited in the study from government and private hospitals, clinics and infertility centres of major cities of four provinces of Pakistan. Age of the participants ranged from 20- 45 years $\left.M_{\text {age }}=32.42, S D=5.49\right)$. The 
educational level of the participants ranged from primary to Post Masters). Participants belonging to lower, middle and upper socioeconomic class were given representation in the study. Most of the participants were cooperative and completed the questionnaires, however, 20 participants left the study incomplete due to personal reasons and their data was excluded from the study and the final sample comprised of 210 women with primary infertility.

Instrument: Social Comparison Scale for Women with Infertility comprising of 32 items was used in the study.

Procedure: Permission from the authorities of the hospital, clinics and fertility centres was sought for administration of indigenously developed scales. Participants were informed about the purpose of study. Informed consent was taken from the participants before administering the scales. Participants were assured for the confidentiality of their responses and it was maintained. Participants were told that there was no time limit to fill in the questionnaire and it took 10 to 15 minutes to complete Social Comparison Scale and 5 to 10 minutes to complete Submissive Behaviour Scale by the participants. They were asked to fill the questionnaires at the spot and queries related to questionnaires were answered to their satisfaction.

Results: To ensure the factor structure and dimensionality of instrument, 32 items of Social Comparison Scale for women with infertility were analyzed through AMOS-21.0. In the present study various indices and criteria were used to describe the best model fit including CFI, TLI, RMSEA, IFI or GFI as they have been commonly reported in recent researches. ${ }^{22}$

The results in Table VI after Confirmatory factor analysis of Social Comparison Scale for Women with Infertility shows that in the final model, the $\mathrm{IFI}=0.9 \mathrm{I}, \mathrm{CFI}=0.9 \mathrm{I}$ together with $X^{2}(317, n=210)=790.71, p<0.01$, and $T L I=0.90$, RMSEA $=0.08$ In terms of the overall indices, it is evident that this model was acceptable. In initial model the values of IFI, TLI, CFI RMSEA were not in acceptable range and model was revised through modification indices and revised model was obtained which still requires further improvement and still the values of $|F|=0.87, T L I=0.86, C F I=0.87$, RMSEA $=0.10$ were not in acceptable range so some items with correlation less than 0.3 were deleted and the final obtained model has all the values in acceptable range. Details of items deleted are: Item 5, "I remain quiet most of the time as compared to child bearing mothers", item8, "I feel that I am not liked by the family as they do other child bearing mothers", item I5, "I feel that family members reject me due to childlessness", item 18, "My husband's love for me has decreased due to childlessness", item 20 , "I feel physically less attractive due to childlessness". In the final model four covariance suggested by Modification Indices, were entered in the error terms to improve the model.

Table VII shows the mean, standard deviation, cronbach's alpha, minimum and maximum scores. It is found that overall alpha for Social Comparison for Women with Infertility SCS-WI is 0.95 ( $\alpha$ range from 0.87 to 0.90 for subscales).

\section{Phase V}

Step I: Test Re Test Reliability: In first step of this phase test re test reliability was found on a sample of 30 women with primary infertility with one month interval which was found to high $(r=$ $0.93, p<0.00 \mathrm{I}$ ) indicating the fact that the scale of social comparison for women with infertility is a reliable measure with sound items homogeneity, internal consistency.

STEP II: Validity Study: In step II validation of Social Comparison Scale for Women with Infertility was done. Convergent validity of SCS-WI was found by correlating it with the similar construct like Social Comparison Scale. ${ }^{13}$ Further, discriminant validity of SCS-WI was determined by correlating it with theoretically opposite scale like Satisfaction with Life Scale as previous studies have shown negative correlation between social comparison and satisfaction with life or low social comparison leads to higher satisfaction with life. ${ }^{23-25}$

Sample: A purposive sample of 37 women with primary infertility for validation study and reliability study were recruited from private hospitals and infertility clinics of Rawalpindi, Lahore and Multan cities of Pakistan.

\section{Instruments}

Social Comparison Scale for Women with primary Infertility: The Social comparison Scale for Women with Infertility is a self report measure consisting of 27 items with three subscales (Social distress, emotional burden and personal incapacity) to assess social comparison (self perception of social rank and relative social standing) among women with infertility. 5 point Likert type scale is the response format of the scale (Never $=0$, slightly disagree $=1$, indecisive $=2$, slightly agree $=3$, strongly agree $=4$ ). A high score indicates that women with

TABLE VIII: MEAN, STANDARD DEVIATION, CRONBACHS ALPHA OF THE SCALES USED IN THE VALIDATION STUDY $(\mathrm{N}=30)$

\begin{tabular}{|l|c|c|c|}
\hline Scale & K & M (SD) & $\boldsymbol{\alpha}$ \\
\hline Social Comparison Scale for Women with Infertility & 27 & $65.23(25.36)$ & 0.93 \\
\hline Satisfaction with life Scale & 5 & $16.87(5.99)$ & 0.85 \\
\hline
\end{tabular}

TABLE IX: CONVERGENT AND DISCRIMINANT VALIDITY OF THE SCS-WI $(\mathbf{N}=30)$

\begin{tabular}{|l|c|c|c|}
\hline Variables & I & $\mathbf{2}$ & $\mathbf{3}$ \\
\hline SCS-WI & I & $0.37^{*}$ & $-0.70^{* *}$ \\
\hline SCS & & I & $-0.30^{*}$ \\
\hline SWLS & & & I \\
\hline
\end{tabular}

SCS-WI=Social comparison Scale for Women with Infertility, SCS=Social Comparison Scale, SWLS=Satisfaction With Life Scale,Note. ${ }^{*} p<0.05 ; * *_{p}<0.01$ 
infertility judges herself as inferior to others, while personal judgment of relative superiority was indicated by a low score. The scale was found to be reliable with overall Cronbach's alpha of 0.95 ( $\alpha$ range from 0.87 to 0.90 for subscales).

The Social Comparison Scale: ${ }^{13}$ The scale measures how one thinks and one stands in relation to others to capture the internal sense of social rank. It is used to assess participants' selfevaluation of their relative social rank compared with others. The II- item self-report scale measures dimensions that focus primarily on judgments of social rank (inferiority-superiority), relative attractiveness, and judgments of group fit. A personal judgement of inferiority was indicated by low scores on this scale, whereas, a low score indicates, a personal judgment of relative superiority. The cronbach alphas of 0.88 and 0.96 with clinical populations and 0.91 and 0.90 with student populations reflect its high reliability. ${ }^{13}$

Satisfaction with Life Scale. ${ }^{26}$ The SWLS with is a 7-point Likert style response scale. The possible range of score is $5-35$ with a score of 20 representing a neutral point on the scale. Scores among 5-9 indicate the respondent is extremely dissatisfied with life, whereas, scores among 3।-35 indicate the respondent is extremely satisfied. The coefficient alpha of the scale ranged from .79 to 0.89 , indicating high internal consistency of the scale. The scale was found to have good test re- test correlations $(0.84,0.80$ over a month interval). Participants respond on a seven point scale ( $I=$ strongly disagree to $7=$ strongly agree) to statements relating to global life satisfaction. It consists of five items. Urdu version was used in this study with Cronbach's alpha $=0.87$. This scale is reported to have high internal consistency, evidence of discriminate and convergent validity and with two month test-retest correlation coefficient of 0.82 . Urdu translated SWLS27 is used in the current study.

Procedure: First permission from hospital authorities was taken and after that purpose of study was communicated to the participants. Informed consent was taken from the participants before administering the scales. Confidentiality of the responses of participants were assured and maintained. Questionnaires were be filled by women with primary infertility whose age range was from 18 years till 45 years and belonged to different socio economic status.

Results: Table VIII shows that overall Cronbach's alpha for Social Comparison Scale for Women with Infertility, Satisfaction with Life Scale were good ( $\alpha$ ranging from 0.85 to 0.93 ). Following are the results for the convergent and discriminant validity of the scales.

Table IX shows inter-correlations among the scales. Pearson product moment correlation was carried out to find the relationship between Social Comparison Scale for Women with Infertility (SCS-WI) with similar construct of social comparison through Social Comparison Scale (SCS) $)^{13}$ and SCS-WI with opposite construct of social comparison i.e., satisfaction with life through Satisfaction with Life Scale(SWLS). Results suggest that SCS$\mathrm{WI}$ positively correlated with similar scale $\left(r=0.37,{ }^{*} p=0.05\right)$, whereas, SCS-WI negatively correlated with SWLS27 $(r=-0.70$, ** $p<0.01)$. The test re-test reliability of SBS-WI after the interval of one month on a sample of 30 women with primary infertility was found to be $\alpha=0.93$.

\section{DISCUSSION}

The study was designed to construct a self report social comparison scale for women with primary infertility. The items for the scale were generated using both inductive and deductive approach. The construct validity of the scale was determined by exploratory factor analysis. Findings show factor loadings of 37 items on three factors (see table III). A principal component analysis followed by orthogonal rotation (Varimax Method) was used. The principal component analysis yielded 3 factor solutions (fixed factor solution) with Eigen values greater than I.0. Those items were retained in the scale whose factor loadings were greater than 0.40 in each sub-scale and five items were deleted whose factor loading were below 0.40 . After EFA, 32 items out of 37 items were retained in the scale. The alpha coefficients of three factors of the scale showed internal consistency and had significant items total correlations and inter-correlations among factors. In order to confirm the factor structure retrieved in EFA, CFA was run on a sample of 210 women with primary infertility. The final model showed fairly acceptable indices (see table VII), so the three factors with all items were retained in the final scale. Thus, the final scale comprised of 32 items with three (factors) sub scales.

Factor I Social Distress measure social experiences of women with infertility. Women who scored high on this factor compare themselves unfavourably with the child bearing mothers and have many negative and intensive social sufferings according to scale psychometric properties. For instance., demotion in rank/status in family (less importance in family), rejection, emotional harassment in homes by family members, social isolation, seclusion, stigmatization, taken for granted for household and other related work by family members, decrease in love by husband, uncooperative attitude of husband, expulsion from home, disruption and dissonance in marital relationship due to social and family pressure on husband for second marriage. These findings are in line with the findings of previous researhes. ${ }^{28-30}$ Moreover, Pakistani women with primary infertility bear tremendous amount of societal pressure for bearing child causing high social distress in them , as bearing children is a pre-requisite for women for strengthening their foothold in their husband's home in our culture and society. Further, women with infertility are subject to a systematic and progressive devaluation. Pakistani women with infertility reported to feel incomplete without child which is similar to the feelings reported by women with infertility in other countries as reported in previous researches. ${ }^{30}$

Further, women with infertility in Pakistan do not have that much respect, importance, social status/rank in family especially in-laws child bearing mothers 
usually have in family. Social isolation and alienation is also reported in interviews by Pakistani women with infertility along with the agony and pain caused by negative comments, dejected disliking and taunts by family especially in-laws and their relatives. They also reported uncooperative attitude of husband towards wife due to infertility, most of the time left alone by husband with decrease in love towards wife and constant threat of second marriage and expelling from home by husband and inlaws etc supported by previous study ${ }^{30}$ that a women's incapability to have children results in the devastation that affects her relationships with husband and other family members and society that leads to deterioration of her social status. In Pakistani society, lots of dissonance regarding marital relationship is found in women with infertility when family pressurizes husband to go for second marriage for children. ${ }^{30}$

The cause of social sufferings for women with primary infertility seems to be negative social comparison as reported in interviews by Pakistani women with primary infertility in the present research which is in line with the findings of researches in other countries especially the developing countries, as Pakistan shares lots of similarities with other developing countries. For instance, the findings of present research that infertility leads to psychological distress as well as an intensive amount of social suffering is supported by previous literature. ${ }^{10}$ The developing countries do not provide sufficient support to such women. Also, the lack of education and inadequate biological understanding about the problem leads to an extensive stigmatization of such women. The findings had shown that loss of social rank is often accompanied with the experience of infertility. Thus, the observation that mostly women's capability to reproduce is linked to her status as women in every culture and society seems to be related with the findings of previous studies ${ }^{30}$ suggesting that the social status of women with infertility can be significant in trivializing the effects of stigmatization and distress associated with infertility.
Second factor of the social comparison scale for women with infertility was "Emotional burden". It measured emotional experiences of women with infertility. Women who scored high on this factor had more emotional issues due to their infertility according to psychometric properties of the scale. The present research is indicative of the fact that more negative emotions are experienced by women with infertility as compared to other child bearing mothers, ranging from excessive crying to feelings of sadness, sorrow, frustration, worry, pity, remorse, grief, shame, embarrassment, feelings of rejection, loneliness and from feelings of helplessness, unhappiness to feelings of hopelessness, despair, boredom, doubt, distress, anxiety, tension, irritability, anger, envy, negative thoughts, depression, loss of interest in daily activities, reduced sexual interest and low confidence. Dissatisfaction with life has also been reported with strong desire for child as their pride. These findings are supported by the findings of previous study $y^{29,30}$ in which they found the effects of infertility which are in the form of psychological distress, feelings of loss of control, problems with identity, issues in beliefs and values, negative emotional reactions and negative effects on social relationships. Sorrow, hopelessness are linked to the feelings of discontent, helplessness, fear, loss and depression. Furthermore, women with primary infertility are reported to engage in more negative thoughts in comparison with child bearing mothers and take their lives as meaningless. The findings of the current study, that Pakistani women with infertility reported to be less happy and less satisfied as compared to child bearing mothers are supported by previous research findings ${ }^{31}$ that life satisfaction was found to be lower along with sexual satisfaction for those women who had qualified the criteria for permanent infertility and those who had an internal locus of control. The association was found to be weaker for those women who were employed. It was found that motherhood is closely associated with higher levels of life satisfaction. However, partner support does help in reducing the negative effects of the condition. The fact that one cannot reproduce effectively in comparison to a large number of people can be emotionally challenging.

The last factor of this scale was "personal incapacities." High score on this scale indicate poor personal abilities of women with infertility like feelings of inferiority, feelings of physical weakness, fatigue, feelings of physical and mental sickness, less resourcefulness, reduced communication, negligence in personal hygiene and care, less capabilities and less eye contact as compared to child bearing mothers. The findings are in line with the previous research that Pakistani women with infertility reported greater depression and somatic symptoms than the women in UK with infertility. ${ }^{32}$ Despite all the negative emotions associated with infertility, only hope for these women is coming from their strong belief in religion Islam that fertility is in the control of Almighty Allah and He will bless them one day is the only source which increases their positive affect and well-being. The findings are supported by previous literature as the finding of the result is in line with customs related to Pakistani culture ${ }^{30,32}$.

The newly developed scale of social comparison scale showed good internal consistency, sound factor structure and high reliability after a month interval. Further, the scale also showed high convergent and discriminate validity.

\section{CONCLUSION}

Thus, in light of above discussion it is concluded that infertility is one of the conditions that affects subjective wellbeing of the women through social comparison especially in the male dominating society of Pakistan. Feelings of being considered as inferior as compared to other women having children in family are torturous and painful for the women with infertility resulting in depression if enough of social support is not available. Moreover, enormous amount of family and societal pressure has been laid upon on couple especially women with primary infertility. Social Comparison Scale for Women with Primary Infertility will be a valuable contribution to assess 
the phenomenon of social comparison in women with primary infertility. This scale has been constructed and then validated in this study with good items homogeneity, sound psychometric properties, high reliability, high internal consistencies and meaningful pattern of validity.

\section{LIMITATIONS}

The results should be interpreted cautiously due to certain limitations. Though, the sample of the study was drawn from major cities of four provinces of Pakistan and represented women with primary infertility from low, middle and high socioeconomic status but women from rural areas and those who were not seeking treatment from any hospital or clinics were not included in the study. Therefore, there is a room to improve the scale properties by expanding the sample to rural areas of Pakistan and from women with primary infertility who is not seeking treatment for any reason.

Future studies may construct a measure to assess social comparison among men with infertility. Measurements used in the study were self-reported, so the factor of common method variance cannot be ignored. The scale should be validated cross-culturally, so that dissimilarities in response to infertility across diverse cultures could be examined.

\section{IMPLICATIONS}

The study suggest family counsellors to develop a proper comprehensive intervention program to effectively deal with negative psychosocial consequences of primary infertility with interventions that promote less social comparison.

The scale developed in the study will open new vistas of research in the domains of social comparison and its correlates and promote research that will validate social rank theory across cultures.

\section{REFERENCES}

I. Inhorn MC, Patrizio P. Infertility around the globe: New thinking on childlessness, gender, and reproductive technologies and global movements in the $21 \mathrm{st}$ century. Hum Reprod Update 2015 Jul-Aug;2I (4):4II-26. DOI: 10.1093/humupd/dmv0

2. Jalil T, Muazzam, A. Emotional intelligence as a predictor of marital adjustment to infertility. Int J Res Stud Psychol 20 I 3;2(3): 45-58.

3. Burns LH, Covington SN, Kempers RD. Infertility counselling. NY: Cambridge University Press; 2006.

4. Crick NR, Grotpeter JK. Relational aggression, gender, and social psychological adjustment. Child Dev 1995 Jun; 66(3):7I0-22. DOI: | 0. I। I।/j. | 467-8624.| 995 . tb00900.

5. Alexander LL, Bader H, Garfield S, LaRosa JH. New dimensions in women's health. $4^{\text {th }}$ ed. Canada: Jones and Bartlett. 2007.

6. Sami N, Ali TS. Perceptions and experiences of women in Karachi, Pakistan regarding secondary infertility: results from a community-based qualitative study. Obstet Gynecol I $n$ t 20।2;20। 2: I08756. DOI: 10.1I55/ $2012 / 108756$.

7. LaRosa J H, Bader H, Alexander W. New dimensions in women's health. Jones \& Bartlett Publishers; Aug 3, 2016.

8. Cousineau TM, Domar AD. Psychological impact of infertility. Best Prac Res Clin Obstet Gynaecol 2007 Apr I ; I (2):293-308.

9. Stephen EH, Chandra A. Declining estimates of infertility in the United States: 1 982-2002. Fertil Steril 2006 Sep; 86(3):5I6-23. DOI: 10.1016/ j.fertnstert.2006.02.129.

10. Crick NR, Grotpeter JK. Relational aggression, gender, and social psychological adjustment. Child Dev 1995 Jun; 66(3):710-22. DOI: I 0.1 I। I/j. I467-8624.1995. tb00900.x.

II. Daar AS, Merali Z. Infertility and social suffering: the case of ART in developing countries. In Vayena E, Rowep PJ, Griffin D (eds). Current practices and controversies in assisted reproduction. 2002. World Health Organization (WHO), Geneva.

12. Joshi H, Singh R, Bindu $M$. Psychological distress, coping and subjective wellbeing among infertile women. J Indian Acad Appl Psychol 2009;35:329-6.

13. Allan S, Gilbert P. A Social Comparison Scale: Psychometric properties and relationship to Psychopathology. Pers Indiv Differ 1995;19(3):293-9. DOI: 10.1016/ 0191-8869(95)00086-L.

14. Mubashir AS, Batool SS. Development and validation of Submissive Behavior Scale for women with Infertility in Pakistan. Pak J Soc \& Clin Psychol 20 I8; I6(I) 10-17.

15. Sultan S, Tahir A. Psychological consequences of infertility. Hellenic JPsychol 20I I;8: 229-47.

16. Hays S. The cultural contradictions of motherhood. Yale University Press, New Haven, CT: 1996.

17. King L, Meyer MH. The politics of reproductive benefits: US insurance coverage of contraceptive and infertility treatments. Gend Soc I 997 Feb; I I(I):8-30.

18. Burisch M. Approaches to personality inventory construction: A comparison of merits. Am Psychol 1984; 39(3):214-27.

19. Stevens A, Price J. Evolutionary psychiatry: A new beginning. I $^{\text {st }}$ Edition. 2000. Routledge / Taylor \& Francis Group, New York.

20. Filed A. Discovering Statistics Using SPSS. $2^{\text {nd }}$ Edition. 2005. SAGE Publications Ltd, London, United Kingdom.

21. Kaiser HF. The application of electronic computers to factor analyses. Educ Psychol Meas 1960;20(I):I4I-5I.

22. McDonald RP, Ho MH. Principles and practice in reporting structural equation analyses. Psychol Methods 2002 Mar;7(I):64-82.

23. Buunk AP, Groothof HA, Siero FW. 
Social Comparison and Satisfaction with one's social life. J Soc Pers Relat 2007 Apr;24(2):197-205. DOI:I0. I I 77/02654075070754I0.

24. Civitci N, Civitci A. Social Comparison Orientation, hardiness and life satisfaction in undergraduate students. Procedia Soc Behav Sci 2015 Oct 9;205:51623. DOI: $10.1016 /$ j.sbspro.2015. 09.062 .

25. Frieswijk N, Buunk BP, Steverink N, Slaets JP. The interpretation of social comparison and its relation to life satisfaction among elderly people: Does frailty make a difference? J Gerontol B Psychol Sci Soc Sci 2004 Sep;59(5):P250-7. DOI: 10.1093/ geronb/59.5.p250.

26. Diener ED, Emmons RA, Larsen RJ,
Griffin S. The satisfaction with life scale. J Pers Assess. 1985 Feb;49(I): 7I-5. DOI: I0.1207/s I5327752 jpa490I_13.

27. Butt MM. Ghani A. Why I am single? Unpublished BS Hons Thesis. Department of Psychology, GC University, Lahore, 2014.

28. Dhingra R, Baru A, Gupta K. Comparing subjective wellbeing of fertile and infertile women residing in the same family. Res Human Soc Sci 2014;4(5):2224-5766.

29. White JB, Langer EJ, Yariv L, Welch JC. Frequent social comparisons and destructive emotions and behaviors: The dark side of social comparisons. J Adult dev $2006 \mathrm{Mar}$ I;I3(I):36-44.
30. Donkor ES, Sandall J. The impact of perceived stigma and mediating social factors on infertility-related stress among women seeking infertility treatment in Southern Ghana. Soc Sci Med 2007 Oct;65(8):1683-94. DOI: 10.1016/ j.socscimed.2007.06.003.

31. McQuillan J, Torres Stone RA, Greil AL. Infertility and life satisfaction among women. J Fam Issu 2007;28(7):955-8I.

32. Batool SS, de Visser R O. Psychosocial and Contextual Determinants of Health among Infertile Women: a cross-cultural Study. Psychol Health Med 20I4; I9(6):673-9. DOI: 10.1080/ | $3548506.20 \mid 4.880492$.

\section{AUTHORS' CONTRIBUTIONS}

Following authors have made substantial contributions to the manuscript as under:

ASM: Study design, acquisition, analysis and interpretation of data, drafting the manuscript, final approval of the version to be published

SB: Conception, acquisition of data, drafting the manuscript, critical revision final approval of the version to be published

Authors agree to be accountable for all aspects of the work in ensuring that questions related to the accuracy or integrity of any part of the work are appropriately investigated and resolved.

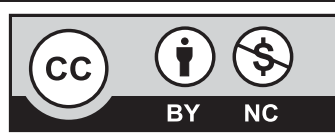

This is an Open Access article distributed under the terms of the Creative Commons Attribution-Non Commercial 2.0 Generic License.

KMUJ web address: www.kmuj.kmu.edu.pk

Email address: kmuj@kmu.edu.pk 